\title{
Representações de "insetos" por crianças do ensino fundamental e implicações para o diálogo nas aulas de ciências naturais
}

\author{
Representations of "insects" by elementary school children and \\ implications for dialogue in natural science classes
}

\author{
Pâmela Gisela Silva Araújo (pamela_gisela@hotmail.com) \\ Universidade Federal da Bahia - UFBA / Universidade Estadual de Feira de Santana - UEFS
}

\author{
Geilsa Costa Santos Baptista (geilsabaptista@gmail.com) \\ Universidade Estadual de Feira de Santana - UEFS
}

\section{Eraldo Medeiros Costa Neto (eraldont@ hotmail.com)} Universidade Estadual de Feira de Santana - UEFS

\begin{abstract}
Resumo: Apresentamos os resultados de um estudo qualitativo que envolveu estudantes do $4^{\circ}$ ano do Ensino Fundamental de uma escola pública do povoado de Pedra Branca, município de Santa Terezinha, Bahia. O objetivo foi investigar como esses estudantes representam os insetos e quais as possíveis implicações para a aprendizagem sobre a biologia desses animais. A coleta de dados aconteceu através de desenhos esquemáticos acompanhados de textos explicativos elaborados pelos estudantes após escutarem a palavra "inseto" e as análises procederam indutivamente, tendo revelado que eles classificam os insetos como sendo animais de um modo geral (espécies da própria classe Insecta e de outros grupos, como crustáceos, mamíferos e peixes, entre outros). Essa classificação revela um ordenamento diferente do científico, podendo estar associado ao universo sociocultural dos estudantes, que se não for considerado nos métodos de ensino escolar, poderá dificultar uma compreensão científica adequada. Consideramos imperativo que os professores investiguem e compreendam os conhecimentos culturais dos estudantes para a promoção de diálogos com negociação de significados culturais e ampliação de conhecimentos que permitam a compreensão cientifica acerca da biologia dos insetos e sua importância ecológica nos diferentes ecossistemas.
\end{abstract}

Palavras-chave: Insetos; Mediações dialógicas; Representações.

Abstract: We present the results of a qualitative study that involved students from the 4th year of elementary school at a Public School in the village of Pedra Branca, municipality of Santa Terezinha, Bahia. The objective was to investigate how these students represent insects and what are the possible implications for learning about the biology of these animals. Data collection took place through schematic drawings accompanied by explanatory texts prepared by students after hearing the word "insect" and the analyzes proceeded inductively, having revealed that they classify insects as being animals in general (species of the class Insecta and other groups, such as crustaceans, mammals and fish, among others). This classification reveals a different order from the scientific one, which may be associated with the socio-cultural universe of students, which, if is not considered in school teaching methods, may hinder and end up hampering an adequate scientific understanding. We consider imperative that 
teachers investigate and understand the cultural knowledge of students in order to promote dialogues with negotiation of cultural meanings and expansion of knowledge that allow scientific understanding about the biology of insects and their ecological importance in different ecosystems.

Keywords: Insects; Dialogical mediations; Representations.

\section{INTRODUÇÃO}

É sabido que as crianças possuem muitas habilidades e muita criatividade em suas ações cotidianas e em seus pensamentos durante seu desenvolvimento. De acordo com Worth (2010), é cada vez mais crescente entre os pesquisadores no assunto a afirmativa de que os pensamentos das crianças exercem fortes influências nas suas aprendizagens, bem como a crença de que a ciência pode ser um domínio particularmente importante na infância, servindo não apenas como uma base para a compreensão científica futura, mas também para construir habilidades e atitudes importantes frente à natureza.

Partindo desse pensamento, podemos entender como os significados são importantes no processo de aprendizagem, e podem ser trabalhados de forma dialogada, motivando os estudantes para ampliar os seus conhecimentos sobre os conteúdos de ciências, dos mais aceitos até aos mais carregados de preconceitos e equívocos, como é o caso dos insetos (Arthropoda: Hexapoda).

Silva e Costa-Neto (2004, p.7) argumentam que "[...] desde os primórdios da humanidade os insetos participam significativa e insistentemente da vida sociocultural da maioria dos grupos étnicos". A relação entre as partes é estabelecida das mais diversas formas, a depender das variáveis culturais envolvidas em cada realidade. De acordo com Morales et al. (1997), fatores como a associação do animal a doenças, benefícios ou prejuízos que o animal possa trazer, ideia de sujeira ou limpeza, conhecimento ou desconhecimento sobre o animal, abundância do animal, aparência, sensação tátil e/ou visual, espiritualidade e crença, são alguns dos muitos aspectos que podem influenciar ou interferir na relação entre os seres humanos e a fauna que os cercam.

No caso dos insetos, sabe-se que, frequentemente, esses animais são conhecidos apenas e/ou principalmente pelas doenças ou outros problemas causados à humanidade, deixando-se geralmente de lado as outras atuações destes seres vivos, por exemplo, o 
papel ecológico que eles desempenham nos ecossistemas (polinização e reprodução de muitas espécies vegetais), bem como benefícios que podem trazer ao homem, como alimentação e para fins fármaco-industriais.

Os significados atribuídos à palavra "inseto" são bem variados e determinados pela cultura de um grupo (COSTA NETO, 1999; PETIZA ET AL., 2003; SILVA E COSTA NETO, 2004). Do ponto de vista da categorização acadêmica, a palavra está bem resolvida e nesse contexto apenas os insetos "reais" e artrópodes correlatos são estudados. No entanto, quando se adota a definição popular, na qual o termo é utilizado de forma ampla para designar diferentes animais além dos artrópodes, tem-se a inclusão de organismos não sistematicamente relacionados com a classe Insecta, tais como mamíferos, répteis, anfíbios, moluscos, aracnídeos, entre outros (Costa Neto, 1999). Parafraseando Posey (1987), as categorias cognitivas não podem ser consideradas como universais e devem ser inferidas usando-se uma abordagem que permita ao professor, em sala de aula, "descobrir" paradigmas conceituais, ao invés de impô-los aos estudantes.

A categorização de animais de diferentes táxons científicos em um mesmo rótulo linguístico parece constituir um padrão da classificação etnozoológica. Este padrão foi explicado pela Hipótese da Ambivalência Entomoprojetiva, segundo a qual, os seres humanos tendem a projetar sentimentos de nocividade, periculosidade, irritabilidade, repugnância e menosprezo a animais não-insetos (inclusive pessoas), associando-os à categoria "inseto" determinada culturalmente (COSTA-NETO, 2000). A ideia de ambivalência é empregada no sentido da sociologia, que se refere à atitude que oscila entre valores diversos e, às vezes, antagônicos. A projeção resulta do processo psicológico pelo qual uma pessoa atribui a outro ser os motivos de seus próprios conflitos. A hipótese é testável através do registro de informações que retratem o caráter emotivo-situacional da percepção de animais rotulados como "insetos", além dos próprios insetos da classificação científica. Segundo Lauck (2002), quando uma projeção está em operação, atribuímos qualidades e motivos ambíguos aos outros seres, criando uma identidade em linha com nossas próprias necessidades e crenças que frequentemente estão bem longe da verdadeira natureza do outro.

De um modo geral, as impressões relacionadas com o lexema salientam os aspectos negativos associados com a visão real ou imaginária de um "inseto". Nas 
localidades mais influenciadas pela mídia, que geralmente mostra que os insetos devem ser exterminados, esses animais são mais notados, porém, sempre com uma conotação negativa (LONGO; PIRES, 1998). Cada vez que a palavra "inseto" é mencionada as pessoas pensam logo naqueles animais que lhes são desagradáveis, como moscas, baratas, aranhas, ratos, escorpiões, sapos e mosquitos. Tal fato é aproveitado pelas indústrias produtoras de praguicidas, que lançam suas campanhas no sentido de combater, indiscriminadamente e cada vez em maior número, esses organismos (RAMOS-ELORDUY, 1994). A própria indústria cinematográfica corrobora essa atitude, pois os filmes raramente projetam imagens positivas dos artrópodes. Ao contrário, eles exploram imagens sinistras de perigo ou morte, imagens chocantes que provocam medo e pavor e imagens caricaturais (antropomorfizadas) para ridicularização (MERTINS, 1986).

Partindo dessa linha de pensamento e reflexão, torna-se imperativo a necessidade do auxílio às pessoas na construção de novos conhecimentos acerca dos insetos, que lhes permitam novas atitudes, ao reconhecer o importante papel desses animais nos ambientes e nas sociedades humanas.

Percebe-se, além dessa problemática, alguns entraves no processo de ensino e de aprendizagem, quando contextualizamos a educação em ciências na realidade brasileira, sendo um deles a falta de sensibilidade do educador às concepções dos estudantes sobre os conteúdos trabalhados. Neste sentido, um dos grandes desafios para o professor de ciências parece ser ensinar os conteúdos científicos, mais especificamente sobre os insetos e, ao mesmo tempo, considerar e respeitar os saberes e as experiências vividas pelos estudantes, que são oriundos de ambientes culturalmente diversos, o que certamente poderá ser facilitado via diálogo intercultural (BAPTISTA e EL-HANI, 2009), entre a maneira como a ciência (entomologia) concebe e representa os insetos e as maneiras como os estudantes concebem e representam os mesmos.

Segundo Lopes (1999), o diálogo é um processo que envolve argumentação e exposição de razões por parte dos interlocutores, que são consideradas e avaliadas por critérios de validade e legitimidade que são próprios dos seus contextos. No diálogo é preciso levar em conta os contextos que dão origem às falas, quais os seus condicionamentos e motivações (LOPES, 1999). Batista (2018) corrobora esta 
afirmativa quando diz que o diálogo se faz necessário para a participação e aprendizagem dos estudantes, atuando como uma estratégia motivacional.

Nas salas de aula de ciências, o diálogo constitui relações que são estabelecidas entre o professor e os estudantes, e entre os estudantes, sobre um determinado tema que é objeto de ensino e aprendizagem, com negociação de significados em contextos culturais específicos (BAPTISTA, 2010).

O diálogo intercultural contribui para o respeito e convivência com as diferenças, partindo de reflexões que são compartilhadas entre os interlocutores, as quais, por sua vez, podem contribuir para que os estudantes tenham uma visão mais crítica e, por conseguinte, para que possam repensar suas atitudes relacionadas com a natureza e seus elementos (BAPTISTA, 2010), como, por exemplo, o medo e repulsa aos insetos, que geralmente são considerados como feios, perigosos ou ameaçadores, tornando-se, assim, mais tolerantes ao convívio com esses animais e evitando prejuízos às suas vidas.

As concepções dos estudantes sobre um determinado objeto/tema podem ser registradas, explicitadas e percebidas de diversas formas, incluindo as representações na linguagem verbal ou não verbal. Para Lemos e Marques (2017), nos desenhos infantis, a sua projeção e operação ultrapassam a sua proposta em sala de aula. Uma vez que as crianças desenvolvem as representações a partir de suas assimilações, elas buscam referências no meio externo e confrontam sua realidade material com a realidade conceituada. Dessa forma, identificamos o desenho como uma forma de representação eficaz para a aprendizagem em ciências e o relacionamos com o diálogo intercultural como uma estratégia de motivação, para o objetivo do processo de ensino e aprendizagem em ciências, mediado pelo professor, o qual, segundo Hilger (2016), é o ator da mediação por meio da negociação de significados e da linguagem.

No presente trabalho, apresentamos e discutimos os resultados de um estudo qualitativo que envolveu crianças que frequentavam o $4^{\circ}$ ano do Ensino Fundamental de uma escola pública localizada no povoado de Pedra Branca, município de Santa Terezinha- BA, em 2009. O objetivo foi investigar como essas crianças representam os insetos e quais as implicações dessas representações para o ensino sobre a biologia desses animais.

\section{MÉTODOS}


Abordagem da pesquisa

A pesquisa aconteceu em 2016 e teve abordagem qualitativa, do tipo estudo de caso, com intervenção pedagógica. De acordo com Gatti e André (2011), a pesquisa qualitativa contribuiu significativamente de forma ampla com o avanço do conhecimento em educação, viabilizando, além da melhor compreensão dos processos escolares, de relações e aprendizagem, processos institucionais e culturais, de socialização e sociabilidade, o cotidiano escolar em suas múltiplas implicações, as formas de mudança e resiliência presentes nas ações educativas, além de destacar mais especificamente, novo sentido à discussão sobre equidade e diversidade.

\section{Caracterização do espaço e sujeitos envolvidos}

O povoado de Pedra Branca está localizado no Médio Paraguaçu, região centrooeste do Estado da Bahia, zona fisiográfica de Feira de Santana, a uma latitude Sul de 12044'30" e longitude Oeste de 39034'50". Dista 202 Km de Salvador e cerca de 13 Km do município de Santa Terezinha, ao qual pertence, localizando-se no sopé da Serra da Jiboia. O clima é subúmido a seco (IBGE, 2019). Os primeiros moradores de Pedra Branca foram os índios Cariri e Sabujas, descendentes dos Tupinambás (CARVALHO, 1995).

Pedra Branca possui 406 moradores, com 136 famílias cadastradas no Posto de Saúde local, sendo a maior concentração entre as faixas etárias de 20 a 39 anos, seguidas de acima de 60 anos. A maioria dos adolescentes (97\%) encontra-se matriculados na rede escolar, e $88 \%$ da população local são alfabetizados (GALVANELOSS, 2013). A agricultura local se baseia na plantação de mandioca (Manihot esculenta Crantz, Euphorbiaceae) e plantação de uva para fabricação de vinho e a pecuária está relacionada à criação de bovinos. Em várias casas são criadas galinhas e patos para consumo familiar; alguns criam porcos e abelhas sem ferrão (Melipona scutellaris e Tetragonisca angustula) para consumo e comércio do mel produzido. Os homens realizam outras tarefas, como construção civil, somente quando há disponibilidade (COSTA-NETO, 2003).

Com relação ao sistema de ensino formal, existe uma escola mantida pela prefeitura que fornece apenas o ensino fundamental, com salas de aula que funcionam com classes multisseriadas. Os estudantes completam seus estudos (ensino médio) nas 
escolas de Santa Terezinha (COSTA-NETO, 2003; SANTOS-FITA, 2008; GALVANE-

LOSS, 2013).

\section{Coleta e análise dos dados}

Os nossos sujeitos de pesquisa foram 32 estudantes, dos gêneros masculino e feminino, com idades entre 10 e 12 anos, que frequentavam o $4^{\circ}$ ano do Ensino Fundamental.

A coleta de dados aconteceu em algumas etapas citadas a seguir. O primeiro passo consistiu em visitas ao espaço escolar e sala de aula a fim de estabelecer ambientação dos estudantes com os pesquisadores e, dessa forma, minimizar os ruídos na execução e resultados da pesquisa. A etapa seguinte foi preparar o ambiente de sala aula com a professora colaboradora, quando os estudantes foram organizados em filas e convidados a realizar desenhos esquemáticos acompanhados de textos explicativos (LUQUET, 1969; PILLAR, 1996), que representassem livremente os seus pensamentos a partir da seguinte questão: - $O$ que vocês imaginam quando escutam a palavra "inseto? Buscamos motivar esses sujeitos a se utilizarem das linguagens verbal e não verbal, considerando que nos espaços das salas de aulas existem estudantes com habilidades específicas para o uso de um ou ambos os tipos de linguagem. Para desenvolver esse trabalho foram utilizados em sala de aula alguns materiais de arte, como papel Ofício A4, lápis grafite e lápis de cor, para os registros feitos pelos estudantes.

Nossas análises procederam sobre os desenhos feitos pelos estudantes, e sobre eles análises indutivas em diálogo com a literatura específica da área de ensino de ciências.

É importante informar que a presente pesquisa teve aprovação do Comitê de Ética em Pesquisa com Seres Humanos da UEFS (CEP-UEFS número 0089.0.05900006/2006 e que a fim de garantir as suas privacidades, os nomes dos estudantes, autores dos desenhos, foram apagados.

\section{RESULTADOS E DISCUSSÃO}

Os resultados indicam que para todos os estudantes participantes, os insetos são animais de um modo geral, tendo sido representados tanto espécies da própria classe Insecta como representações de outros grupos animais, como crustáceos, mamíferos, peixes, répteis e aves (Figura 1). 


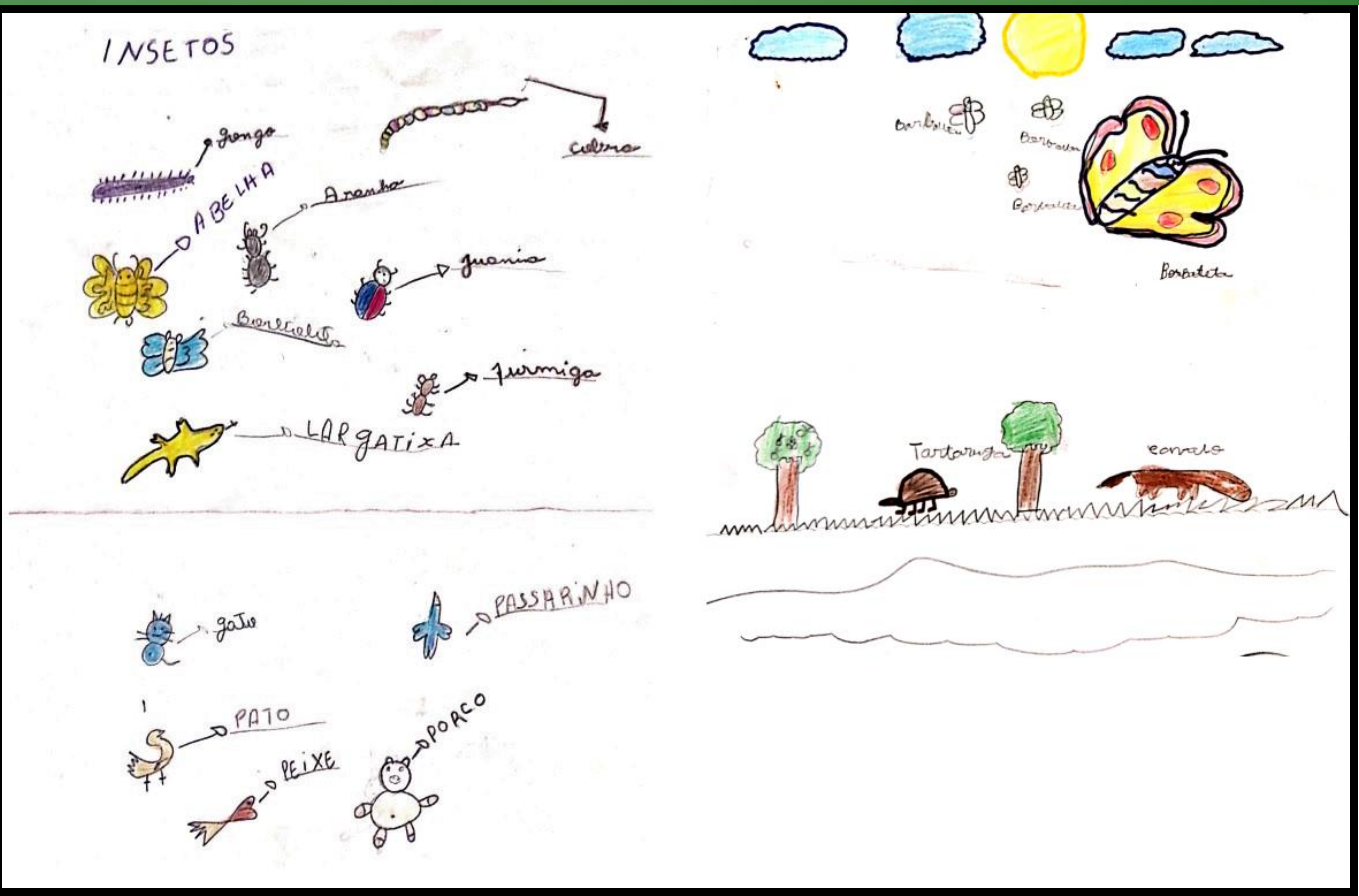

Figura 1. Desenhos realizados pelos estudantes participantes representando os insetos.

Entre os desenhos e explicações textuais, encontramos insetos popularmente nomeados de moscas, baratas, formigas, borboletas e joaninhas (Figuras 1, 2 e 3), sendo estes, em alguns casos, acompanhados por frases de repulsa (Figuras 3), por causar dados à vida humana, e em outros por afetividade, como exemplo as borboletas, possivelmente por suas cores e beleza (Figura 2).

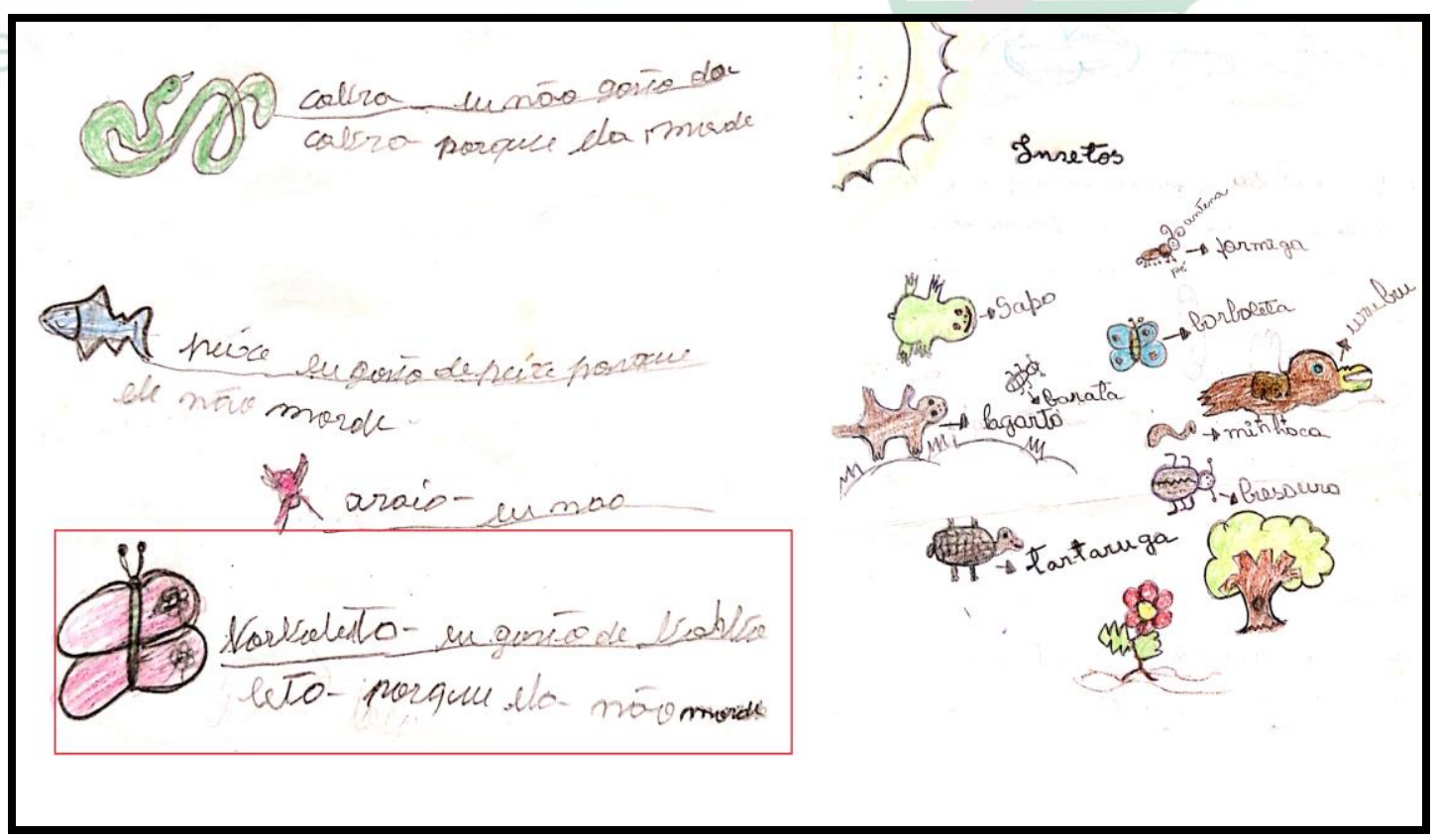

Figura 2. Desenhos realizados pelos estudantes participantes indicando nomes populares de insetos e escrita indicando sentimento de afetividade em destaque. 


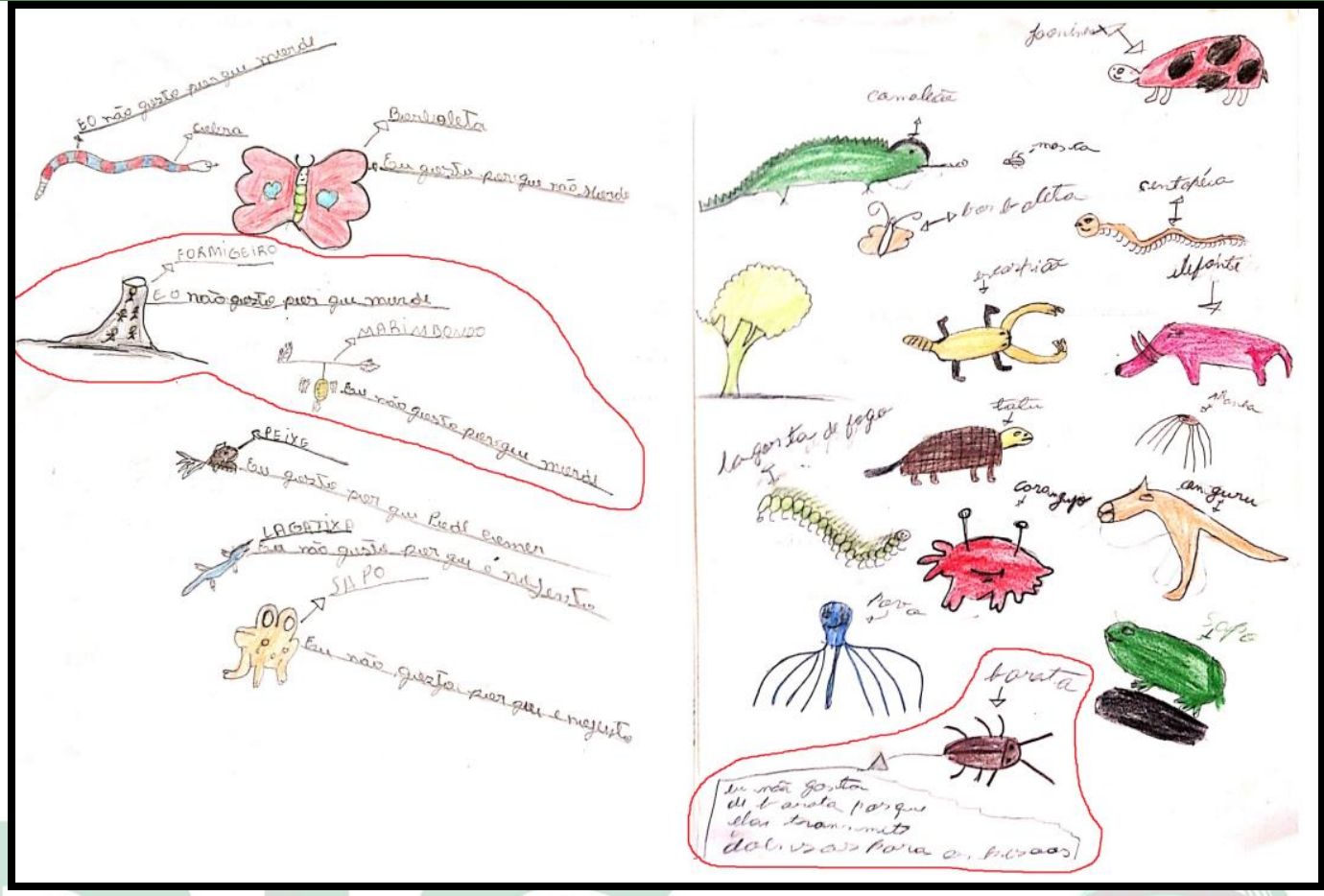

Figura 3. Desenhos realizados pelos estudantes participantes acompanhados de frases de repulsa por causar dados à vida humana e destaque.

Tendo em vista que este momento de pesquisa não foi conduzido em formatos didático-pedagógico em ciências, mas sim uma intervenção na sala de aula para coleta de dados da nossa pesquisa, que partiu de uma única questão e instruções para a realização dos desenhos, podemos inferir algumas possibilidades que levaram os estudantes a realizarem os desenhos apresentados nas figuras acima. Entre elas está a possibilidade de que as aulas de ciências não tenham a perspectiva intercultural de dialogar os saberes científicos com os saberes inerentes aos meios socioculturais dos estudantes, levando-os à construção de conhecimentos equivocados do ponto de vista científico. Isto, por sua vez, pode ser resultante da formação inicial e/ou continuada dos professores da escola que, na construção dos seus sabres da docência não tiveram a devida atenção às diversas culturas presentes nas salas de aula e da importância de considera-las nos momentos de ensino e a aprendizagem, para que esses sujeitos consigam o domínio da linguagem científica, diferenciando-a daquela que faz parte dos seus cotidianos. É preciso uma formação docente que considere a realidade desses estudantes, que são provenientes do campo, uma realidade que segundo Silveira da Rosa e Robaina (2020), “[...] ocorre em espaços denominados rurais nos municípios, e diz respeito a todo espaço educativo que se dá em áreas fora da zona urbana." 
Um professor sensível à diversidade tem potencial e respaldo para uma abordagem que valorize e respeite às diferenças culturais, dos pensamentos e falas, das atitudes e representações por parte dos estudantes. Isto torna-se possível pela promoção do diálogo intercultural, entre a cultura da ciência e as culturas dos estudantes, estabelecendo relações de semelhanças e de diferenças em termos epistemológicos e ontológicos (BAPTISTA, 2010). O diálogo, além de acolher culturalmente o estudante, motiva as suas participações, promovendo a ampliação de saberes, ou a mudança de perfil conceitual. Como bem argumenta El-Hani (2001), o ensino de ciências torna-se relevante quando não tenta promover a mudança dos conceitos culturais dos sujeitos, mas sim, o seu perfil conceitual, quando acrescentará novos conceitos nas suas estruturas cognitivas.

A relação didático-pedagógico e ausência do diálogo intercultural pode ter sido um fator determinante para as representações dos estudantes nos seus desenhos, pois todos tiveram reações semelhantes em seus registros gráficos, concebendo os insetos como animais de um modo geral, classificando-os por um ordenamento diferente daquele utilizado cientificamente. Além disto, é possível que esses estudantes tenham dificuldades de classificar cientificamente, especialmente dentro do contexto escolar, por não terem relações com as terminologias dos seus ambientes sociais, o termo inseto foi utilizado de maneira generalizável. Esse fato pode demonstrar como os significados são determinantes na formação do pensamento, na forma de perceber e explicar os fenômenos da natureza e os conceitos científicos. De igual forma, como a uma abordagem pedagógica intercultural nas salas de aula pode favorecer a compreensão da ciência que está sendo ensinada. Para os professores de ciências precisam gerar oportunidades às crianças de apropriação e domínio de conhecimentos relacionados à Ciência, conhecendo seus significados para que possam ler o mundo à sua volta e atuar nele de forma consciente, especialmente nas sociedades cientifica e tecnologicamente influenciadas (SOARES e GONÇALVES, 2015).

Analisando as possibilidades, podemos ainda considerar, mesmo que remotamente, que tenha existido alguma falha na comunicação entre os pesquisadores e os estudantes, e estes não tenham compreendido bem a proposta da pesquisa, na pergunta investigativa, seja na entonação e/ou volume da voz, ou no modo de se 
reportar aos estudantes, fazendo com que estes tenham direcionado suas representações para os animais no geral.

É preciso observar que as sociedades tradicionais constroem suas classificações levando em consideração não apenas o seu conhecimento acerca das espécies biológicas (dimensão cognitiva), mas também os sentimentos (dimensão afetiva), as crenças (dimensão ideológica) e os comportamentos (dimensão etológica) que intermediam as interações dos seres humanos com os recursos faunísticos de seu meio ambiente (MARQUES, 1995).

A "descoberta" de termos cognitivos para rotular organismos como "insetos" tem implicações na construção desse domínio, uma vez que os seres humanos normalmente odeiam os insetos por razões óbvias: eles invadem residências e corpos (invasão de privacidade); alguns realmente são uma ameaça séria à saúde e bem-estar, causando danos diretos e indiretos (MUMFORD, 1982; HARDY, 1988). No entanto, mais de 99,9\% de todas as espécies de insetos são diretamente benéficas aos seres humanos ou ao menos não lhes causam malefícios (Moore et al., 1982). Mesmo insetos daninhos raramente são perigosos quando estão presentes em número populacional baixo e podem ser uma fonte de alimento para populações de inimigos naturais benéficos. Todavia, para uma percentagem relativamente pequena da população, a visão de um inseto provoca um pânico cego ou um terror desvairado (BERENBAUM, 1995).

\section{CONSIDERAÇÕES FINAIS}

Concluímos que essas representações podem estar associadas ao universo sociocultural no qual os estudantes estão inseridos, que percebem os animais e os classificam por um ordenamento diferente daquele utilizado cientificamente, sendo, para eles, portanto, difícil classificar especificamente dentro do contexto escolar o que seriam os insetos. Outra possibilidade é a de que embora os insetos sejam trabalhados como conteúdo de ensino, a forma como foi trabalhada não foi associada às suas realidades, não lhes fazendo sentido algum o termo.

Por fim, é possível que os estudantes não tenham compreendido bem a nossa pergunta, direcionando suas representações para os animais no geral. Consideramos tais achados de suma importância para que os professores estejam atentos à importância de investigar e compreender as concepções dos estudantes, as quais necessitam de 
mediações dialógicas no sentido de levá-los à reflexão de que, para a ciência, nem todos os organismos são considerados insetos e quais as razões para isto. De igual forma, que os insetos, assim como todos os seres vivos, incluindo os humanos, participam das relações ecológicas existentes na natureza e, portanto, possuem funções fundamentais para a manutenção da vida nos ecossistemas.

Os resultados discutidos neste trabalho são de suma importância para que os professores estejam atentos à importância de investigar e compreender as concepções dos estudantes, as quais necessitam de mediações dialógicas no sentido de levá-los à reflexão de que, para a ciência, nem todos os organismos são considerados insetos e quais as razões para isto. De igual forma, que os insetos, assim como todos os seres vivos, incluindo os humanos, participam das relações ecológicas existentes na natureza e, portanto, possuem funções fundamentais para a manutenção da vida nos ecossistemas.

\section{REFERÊNCIAS}

BAPTISTA, G. C.; EL-HANI, C. N. The contribution of ethnobiology to the construction of a dialogue between ways of knowing: a case study in a Brazilian public high school. Science \& Education, Bauru, v. 18, n. 3-4, p. 1-18, 2009.

BAPTISTA, G. C. S. Importância da demarcação de saberes no ensino de ciências para sociedades tradicionais. Ciência \& Educação, Bauru, v. 16, n. 3, p. 679-694, 2010.

BAPTISTA, G. C. S. Tables of contextual cognition: a proposal for intercultural research in science education. Cultural Studies of Science Education, Nova York, v. 13, p. 845-863, 2018.

BERENBAUM, M. R. Bugs in the system: insects and their impact on human affairs. Massachusetts: Perseus Books, 1995.

CARVALHO, M. R. As revoltas indígenas na aldeia da Pedra Branca no século XIX. In: REIS, E.; ALMEIDA, M. H. T.; FRY, P. (coords.). Pluralismo, espaço social e pesquisa. São Paulo: Hucitec, 1995. p. 272-290.

COSTA NETO, E. M. A etnocategoria "inseto" e a hipótese da ambivalência entomoprojetiva. Acta Biológica Leopoldensia, São Leopoldo, v. 21, n. 1, p. 7-14, 1999. 
COSTA NETO, E. M. Biotransformações de insetos no povoado de Pedra Branca, estado da Bahia, Brasil. Interciencia, Caracas, v. 29, n. 5, p. 280-283, 2004.

COSTA-NETO, E. M. The significance of the category 'insect' for folk biological classification systems. Journal of Ecological Anthropology, Tampa, v. 4, p. 70-75, 2000 .

EL-HANI, C. N. Por que a etnobiologia e a etnoecologia são importantes? Uma resposta do ponto de vista da educação. In: COSTA-NETO, E. M. \& SOUTO, F. J. B. (Orgs). Anais do I Encontro Baiano de Etnobiologia e Etnoecologia. Feira de Santana: UEFS - Universidade Estadual de Feira de Santana, 2001, p. 91-108.

GALVAGNE-LOSS, A. T. Etnoornitologia no povoado de Pedra Branca, município de Santa Teresinha, Bahia. 2013. 105 f. Dissertação (pós-graduação em Zoologia), Universidade Estadual de Feira de Santana, Feira de Santana, 2013.

GATTI, B. A.; ANDRÉ, M. A relevância dos métodos de pesquisa qualitativa em educação no Brasil. In: WELLER, W.; PFAFF, N. (Orgs.). Metodologias da pesquisa qualitativa em Educação: teoria e prática. 2. ed. Petrópolis: Vozes, 2011. p. 29-38.

HARDY, T. N. Entomophobia: the case for miss Muffet. Bulletin of the Entomological Society of America, Palo Alto, v. 34, n. 2, p. 64-69, 1988.

HILGER, T. R. Aprendizagem significativa. Aprendizagem Significativa em Revista, Porto Alegre, v. 6, n. 3, p. 01-19, 2016.

IBGE. INSTITUTO BRASILEIRO DE GEOGRAFIA E ESTATÍSTICA. Cidade: Santa Teresinha, Bahia. Disponível em: <http://www.ibge.gov.br/cidadesat>. Acessado em: $01 \mathrm{dez} 2019$.

LAUCK, J. E. The voice of the infinite in the small: re-visioning the insect-human connection. Boston: Shambhala Publications, 2002.

LEMOS, C. O. de A.; MARQUES, T. O. Representações gráficas no ensino de geografia: um auxílio à educação ambiental nos anos iniciais. Revista Tamoios, Rio de Janeiro, v. 13, n. 2, p. 61-77, 2017.

LONGO, P. L., PIRES, J. S. R. Análise da percepção em relação à fauna encontrada próxima ou dentro das casas de estudantes de diferentes localidades - São Paulo, São Carlos e Água Vermelha. In: SIMPÓSIO BRASILEIRO DE ETNOBIOLOGIA E 
ETNOECOLOGIA, 2., 1998, São Carlos. Resumos... São Carlos: UFSCar, 1998. p. 113.

LOPES, A. R. C. Pluralismo cultural em políticas de currículo nacional. In: MOREIRA, A. F. B. (Org.). Currículo: políticas e práticas. Campinas: Papirus, 1999. p. 59-80.

LUQUET, G. H. Arte Infantil. Lisboa: Companhia Editora do Minho SA, 1969.

MARQUES, J. G. W. Pescando pescadores: etnoecologia abrangente no baixo São Francisco alagoano. São Paulo: NUPAUB-USP, 1995.

MERTINS, J. W. Arthropods on the screen. Bulletin of the Entomological Society of America, Palo Alto, v. 32, p. 85-90, 1986.

MOORE, W. S. et al. What are magazine articles telling us about insects? Journalism Quarterly, Athens, v. 59, n. 3, p. 464-466, 1982.

MORALES, A. G. et al. Estudo comparativo das atitudes de estudantes de Assis, SP, frente aos animais invertebrados. In: JORNADA DE EDUCAÇÃO, 4., 1997, Assis. Resumos... Assis: Unesp, 1997. p. 2.

MUMFORD, J. Entomophobia: the fear of arthropods. Antenna, Londres, v. 6, n. 1, p. 156-157, 1982.

PETIZA, S.; HAMADA, N.; BRUNO, A. C.; COSTA NETO, E. M. Etnotaxonomia entomológica Baniwa na cidade de São Gabriel da Cachoeira, estado do Amazonas, Brasil. Amazônica Revista de Antropologia, v. 5, n. 3, p. 708-732, 2013.

PILLAR, A. D. Desenho \& escrita como sistema de representação. Porto Alegre: Artemédicas, 1996.

POSEY, D. A. Temas e inquirições em etnoentomologia: algumas sugestões quanto à geração de hipóteses. Boletim Museu Paraense Emilio Göeldi, Série Antropologia, v. 3, n. 2, p. 99-134, 1987.

RAMOS-ELORDUY, J. ¿Usted ya probó los insectos comestibles? UNAM hoy, Cidade do México, v. 3, n. 12, p. 61-66, 1994.

SANTOS-FITA, D. Cobra é inseto que ofende: classificação etnobiológica, questões sanitárias e conservação na região da Serra da Jibóia, Estado da Bahia, Brasil. 2008. 133 f. Dissertação (pós-graduação em Zoologia), Universidade Estadual de Santa Cruz, Ilhéus, 2008. 
SILVA, T. F. P.; COSTA NETO, E. M. Percepção de insetos por moradores da comunidade de Olhos d'Água, município de Cabaceiras do Paraguaçu, Bahia, Brasil.

Boletin de la Sociedad Entomológica Aragoneza, Zaragoza, n. 35, p. 261-268, 2004. SILVEIRA DA ROSA, S.; ROBAINA, J. O Ensino de Ciências nas Escolas do

Campo a partir da análise da produção acadêmica. Revista Insignare Scientia - RIS, v. 3 , n. 2, p. 156-175, 24 ago. 2020.

SOARES, G. F. A; GONÇALVES, T. V.A. Pesquisa em aulas de ciências: um desafio aos professores dos anos escolares iniciais. Polyphonía, v. 26, n. 1, p. 143-149, 2015.

WORTH, K. Science in early childhood classrooms: content and process. In SEED: Collected Papers. Early Childhood Research Practice, v. 12, n. 2, 2010. Disponível em: $<$ https://ecrp.illinois.edu/beyond/seed/worth.html>. Acesso em: 22 out 2020.

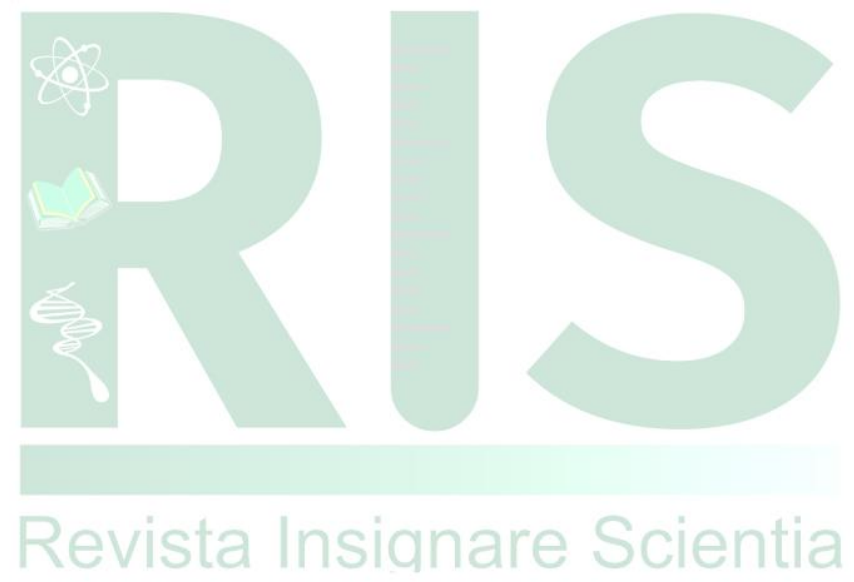

